\title{
Social inequalities and cancer: can the European deprivation index predict patients' difficulties in health care access? a pilot study
}

\author{
Guillaume Moriceau ${ }^{1,2}$, Aurélie Bourmaud ${ }^{2,3}$, Fabien Tinquaut ${ }^{2}$, Mathieu Oriol ${ }^{2}$, \\ Jean-Philippe Jacquin ${ }^{1}$, Pierre Fournel ${ }^{1}$, Nicolas Magné ${ }^{4}$ and Franck Chauvin ${ }^{2,3,5}$ \\ ${ }^{1}$ Medical Oncology Lucien Neuwirth Cancer Institute, Saint Priest en Jarez, France \\ 2 Department of Public Health, Hygée Centre, Lucien Neuwirth Cancer Institute, Saint Priest en Jarez, France \\ 3 Therapeutic Targeting in Oncology, EMR3738, Claude Bernard University, Lyon, France \\ ${ }^{4}$ Radiation Oncology Lucien Neuwirth Cancer Institute, Saint Priest en Jarez, France \\ ${ }^{5}$ Clinical Investigation Center and Clinical Epidemiology, Jean Monnet University, Saint-Etienne, France \\ Correspondence to: Aurélie Bourmaud, email: aurelie.bourmaud@icloire.fr \\ Keywords: cancer, access to care, socio-economic inequalities, european deprivation Index, population based \\ Received: July 17, $2015 \quad$ Accepted: September 30, $2015 \quad$ Published: November 02, 2015
}

This is an open-access article distributed under the terms of the Creative Commons Attribution License, which permits unrestricted use, distribution, and reproduction in any medium, provided the original author and source are credited.

\section{ABSTRACT}

Context: The European Deprivation Index (EDI), is a new ecological estimate for Socio-Economic Status (SES). This study postulates that Time-To-Treatment could be used as a cancer quality-of -care surrogate in order to identify the association between cancer patient's SES and quality of care in a French comprehensive cancer center.

Methods: retrospective mono-centered cohort study. All consecutive incoming adult patients diagnosed for breast cancer(BC), prostate cancer(PC), colorectal cancer (CRC), lung cancer(LC) or sarcoma(S) were included between January 2013 and December 2013. The association of EDI and Time-To-Diagnosis(TTD), as well as TimeTo-Treatment(TTT) was analyzed using a cox regression, and a strata analysis per tumor site was performed.

Results: 969 patients were included. Primitive tumor site was 505 BC(52\%), 169 PC(17\%), 145 LC(15\%), 116 CRC(12\%), and 34 S(4\%). Median TTD was 1.41 months (Q1-Q3 0.5 to 3.5 months). Median TTT was 0.9 months $(0.4-1.4)$. In a multivariate analysis, we identified the tumor site as a predictive factor to influence TTD, shorter for BC (0.75months, [0.30-1.9]) than PC (4.69 months [1.6-29.7]), HR 0.27 95\%CI= $[0.22-0.34], p<0.001$. TTT was also shorter for BC (0.75months [0.4-1.1]) than PC (2.02 [0.9-3.2]), HR 0.32 95\%CI= [0.27-0.39], $p<0.001$. EDI quintiles were not found associated with either TTT or TTD.

Conclusions: Deprivation estimated by the EDI does not appear to be related to an extension of the Time-to-Diagnosis or Time-to-Treatment in our real-life population. Further research should be done to identify other frailty-sensitive factors that could be responsible for delays in care.

\section{INTRODUCTION}

In a redistributive health care system, the aim of social health insurance is to provide equal access to health care to all insurees, in order to reduce or at least to avoid creating more social inequalities. Yet this objective is not reached in numerous developed countries, benefiting from National Health Insurance. Evidence has been given to inequalities in health care and documented worldwide, especially in France, where social inequities are among the highest in Europe [1,2].

Nowadays, cancer is the second cause of death by 
non-communicable diseases in the world and the first cause of mortality in France [3]. An association has been identified between patients 'Socioeconomic Status' (SES) and different cancer outcomes. Studies from various countries highlighted a significant impact of the SES on cancer diagnosis [4-6], treatment [7, 8], mortality [9-13] and cancer survivors' rehabilitation [14] : the lower the SES is, the worse the outcome is. Socioeconomic Status has also been demonstrated to be linearly related to cancer screening attendance [15-20]. But few studies observed this phenomenon in France [21-23]. Furthermore, few studies have evaluated the association between SES and the time between symptoms to diagnosis or between diagnosis to first hospital care [24, 25] and none of them are French. Yet these indicators have demonstrated to be good surrogates of quality-of-care [26-28].

The majority of the studies dealing with cancer inequities used an ecological index of social deprivation to estimate patients' socio-economic status in order to identify the relation between SES and cancer outcomes.
The most used is the Townsend index. This index is defined as "a state of observable and demonstrable disadvantages relative to the local community or more widely to the society to whom the patient, family or group belongs" [29].In France, the use of this Index to estimate SES highlighted a low impact of the "deprivation" on cancer outcomes [30]. The limits raised by this study were that this index was too rough to capture individual and community specificities.

Recently, a new ecological deprivation index, the European Deprivation Index (EDI), has been developed [31]. This Index is a better match to patients' cultural and social environment since it is constructed and tailored for each European country. But the EDI can also be replicated in 24 other European countries, and used to perform international comparisons.

We postulate that EDI could be a better estimator of SES than the Towsend Index. We also postulate that since time-to-treatment has demonstrated to be associated with quality of care, it could be used as a cancer outcome

Table 1: Characteristics of patients

\begin{tabular}{|c|c|c|c|}
\hline $\mathbf{n}$ & 969 & $\underline{\mathbf{n}}$ & 969 \\
\hline Age (years) & & Perform ance status at baseline & \\
\hline Median [Q1-Q3] & $65[55-74]$ & 0 & $612(63 \%)$ \\
\hline Mean (SD) & $63.9(13.2)$ & 1 & $257(27 \%)$ \\
\hline Range & 19 to 92 & 2 & $72(7 \%)$ \\
\hline Gender & & $=3$ & $21(2 \%)$ \\
\hline Female & $608(63 \%)$ & missing & $7(1 \%)$ \\
\hline Male & $361(37 \%)$ & Deadline of referral, $m$ onths & \\
\hline Year of diagnosis & & & $1.41[0.5-$ \\
\hline & 969 & Time to diagnosis, median [Q1-Q3] & 3.5] \\
\hline 2013 & $(100 \%)$ & & $0.9[0.4-$ \\
\hline Primitive tum or & & Time to treatment, median [Q1-Q3] & 1.4] \\
\hline Breast & $505(52 \%)$ & First treatment started & \\
\hline Prostate & $169(17 \%)$ & surgery & $584(60 \%)$ \\
\hline Lung & $145(15 \%)$ & chemotherapy & $148(15 \%)$ \\
\hline Colon or rectum & $116(12 \%)$ & hormone therapy & $112(12 \%)$ \\
\hline Sarcoma & $34(4 \%)$ & radiotherapy & $65(7 \%)$ \\
\hline T staging at diagnosis & & radio- & \\
\hline in situ & $10(1 \%)$ & chemotherapy & $40(4 \%)$ \\
\hline 1 & $381(39 \%)$ & best supportive & \\
\hline 2 & $252(26 \%)$ & care & $8(1 \%)$ \\
\hline 3 & $147(15 \%)$ & missing & $8(1 \%)$ \\
\hline 4 & $68(7 \%)$ & Last know status (at 1 January 2014) & \\
\hline$x$ & $21(2 \%)$ & Death & $33(3 \%)$ \\
\hline missing & $75(8 \%)$ & Censored & $350(36 \%)$ \\
\hline $\mathrm{N}$ staging at diagnosis & & Alive & $586(60 \%)$ \\
\hline 0 & $527(54 \%)$ & Ecological Deprivation Index* & \\
\hline 1 & $207(21 \%)$ & Quintile 1: the least deprived & $129(13 \%)$ \\
\hline 2 & $100(10 \%)$ & Quintile 2 & $201(21 \%)$ \\
\hline 3 & $27(3 \%)$ & Quintile 3 & $166(17 \%)$ \\
\hline $\mathrm{X}$ & $28(3 \%)$ & Quintile 4 & $185(19 \%)$ \\
\hline missing & $67(7 \%)$ & Quintile 5: the most deprived & $279(29 \%)$ \\
\hline M staging at diagnosis & & missing & $9(1 \%)$ \\
\hline 0 & $794(82 \%)$ & \multirow{4}{*}{\multicolumn{2}{|c|}{$\begin{array}{l}\text { Aggregate variable of the neighborhood, French } \\
\text { version }\end{array}$}} \\
\hline 1 & $170(18 \%)$ & & \\
\hline$X$ & $4(0 \%)$ & & \\
\hline missing & $1(0 \%)$ & & \\
\hline
\end{tabular}


Table2: Time-To-Diagnosis univariate and multivariate analyses

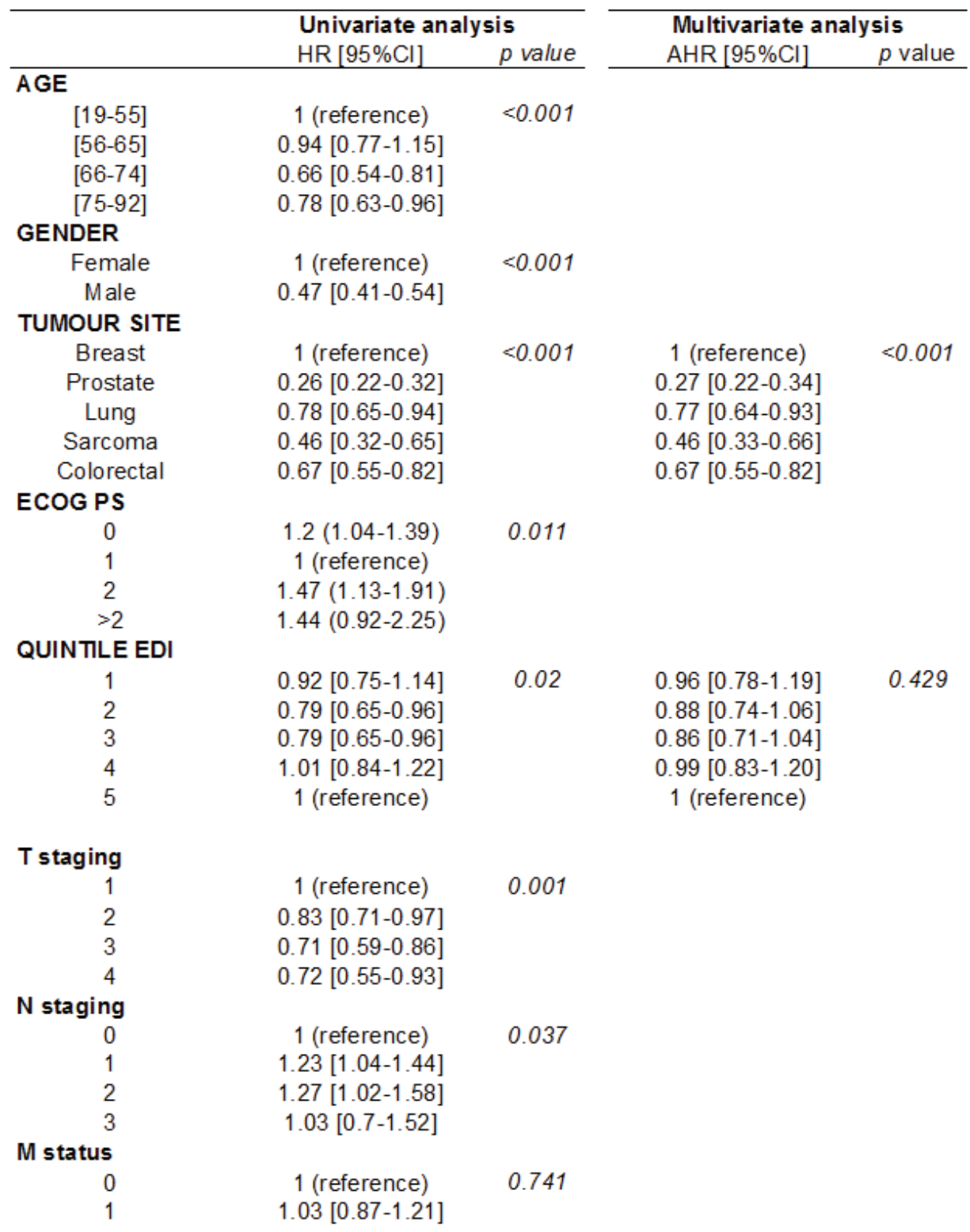

surrogate in this study. Thus, the objective of this study is to identify the association between cancer patient's deprivation and quality of care in a French comprehensive care centre. The principal objective was to measure the influence of patients' SES, estimated by the EDI, on the time-to-diagnosis (time between onset of symptoms and first histological evidence) in newly diagnosed patients. The secondary objectives were to identify associations between deprivation and Time-to-Treatment (time between diagnosis and first specialized medical or surgical treatment) and other outcomes.

\section{RESULTS}

In civil year 2013, 969 patients were admitted to our institution for a diagnosis of BC, PC, CRC, LC or S.
All of them had histological proved malignancies. Median age was 65 years (Table 1). 505 patients had breast cancer $(52 \%), 169$ had prostate cancer $(17 \%), 145$ had lung cancer (15\%), 116 had colorectal cancer C (12\%), and 34 had sarcoma (4\%). $82 \%$ patients had no metastatic disease at diagnosis. Performance status at baseline was 0 for 612 patients $(63 \%)$ and $\geq 3$ for 21 patients $(2 \%)$.

Median Time-To-Diagnosis was 1.41 months [Q1Q3 ranging 0.5 to 3.5 months] for all cancers $(0.75$ months [0.3-1.9] for BC, 4.69 months [1.6-29.7] for PC, 1.54 months [1-2.7] for LC, 1.90 months [0.8-1.2] for CRC and 2.75 months [1.6-7.0] for $\mathrm{S}$ (Figure 1). Median TimeTo-Treatment was 0.9 month [Q1-Q3 ranging 0.4 to 1.4 months] for all cancers and 0.75 months [0.4-1.1] for $\mathrm{BC}$, 2.02 months [0.9-3.2] for PC, 0.79 months [0.4-1.3] for LC, 0.79 months [0.3-1.4] for CRC and 0.34 months [0- 
Table 3: Time-To-Treatment univariate and multivariate analyses

\begin{tabular}{|c|c|c|c|c|}
\hline & \multicolumn{4}{|c|}{ Time to treatment } \\
\hline & \multicolumn{2}{|c|}{ Univariate analysis } & \multicolumn{2}{|c|}{ Multivariate analysis } \\
\hline & $\mathrm{HR}[95 \% \mathrm{Cl}]$ & $p$ value & $\operatorname{AHR}[95 \% \mathrm{Cl}]$ & $p$ value \\
\hline \multicolumn{5}{|l|}{ AGE } \\
\hline$[19-55]$ & 1 (reference) & $<0.001$ & & \\
\hline$[56-65]$ & $0.72[0.6-0.87]$ & & & \\
\hline$[66-74]$ & $0.6[0.51-0.72]$ & & & \\
\hline$[75-92]$ & $0.73[0.61-0.88]$ & & & \\
\hline \multicolumn{5}{|l|}{ GENDER } \\
\hline Female & 1 (reference) & $<0.001$ & & \\
\hline Male & $0.46[0.4-0.53]$ & & & \\
\hline \multicolumn{5}{|l|}{ TUMOUR SITE } \\
\hline Breast & 1 (reference) & $<0.001$ & 1 (reference) & $<0.001$ \\
\hline Prostate & $0.32[0.26-0.39]$ & & $0.32[0.27-0.39]$ & \\
\hline Lung & $0.76[0.63-0.93]$ & & $0.75[0.62-0.92]$ & \\
\hline Sarcoma & $0.7[0-5.1]$ & & $0.7[0.49-0.99]$ & \\
\hline Colorectal & $0.81[0.66-0.99]$ & & $0.81[0.66-0.99]$ & \\
\hline \multicolumn{5}{|l|}{ ECOG PS } \\
\hline 0 & $0.56[0.36-0.86]$ & 0.046 & & \\
\hline 1 & $0.53[0.34-0.83]$ & & & \\
\hline 2 & $0.65[0.4-1.06]$ & & & \\
\hline$>2$ & 1 (reference) & & & \\
\hline \multicolumn{5}{|l|}{ QUINTILE EDI } \\
\hline 1 & 1 (reference) & 0.324 & 1 (reference) & 0.982 \\
\hline 2 & $0.84[0.67-1.05]$ & & $0.98[0.78-1.22]$ & \\
\hline 3 & $0.98[0.78-1.23]$ & & $1.04[0.82-1.31]$ & \\
\hline 4 & $0.99[0.79-1.24]$ & & $0.99[0.79-1.2]$ & \\
\hline 5 & $1.0023[0.81-1.24]$ & & $0.98[0.79-1.21]$ & \\
\hline \multicolumn{5}{|l|}{ T staging } \\
\hline 1 & 1 (reference) & $<0.001$ & & \\
\hline 2 & $0.81[0.7-0.95]$ & & & \\
\hline 3 & $0.84[0.7-1.02]$ & & & \\
\hline 4 & $1.54[1.2-2]$ & & & \\
\hline \multicolumn{5}{|l|}{ N staging } \\
\hline 0 & 1 (reference) & $<0.001$ & & \\
\hline 1 & $1.33[1.1-1.6]$ & & & \\
\hline 2 & $1.5[1.2-1.8]$ & & & \\
\hline 3 & $1.2[0.8-1.8]$ & & & \\
\hline \multicolumn{5}{|l|}{ M status } \\
\hline 0 & 1 (reference) & $<0.001$ & & \\
\hline 1 & $1.58[1.34-1.87]$ & & & \\
\hline
\end{tabular}

1.8] for $\mathrm{S}$ (Figure 1). Surgery was the most frequent first treatment $(N=588,61 \%)$, then chemotherapy $(N=148$, $15 \%)$, hormonal therapy $(N=112,12 \%)$ and radiotherapy $(N=65,7 \%) .129$ patients $(13 \%)$ were included in the quintile 1 of the EDI (the least deprived), $201(21 \%)$ in the quintile $2,166(17 \%)$ in the quintile $3,185(19 \%)$ in the quintile 4 and 279 patients (29\%) lived in quintile 5- area, the most deprived.

Univariate associations between patients' characteristics and Time-To-Diagnosis are reported on Table 2. EDI quintile $2 / 3$ are associated with a shorter Time-To-Diagnosis compared to quintile 5 (36 vs 48 days, HR $0.79,95 \% \mathrm{CI}=[0.65-0.96], p=0.02)$. After elimination of correlated variables, multivariate analysis
(Table 2) did not identify EDI as being associated with Time-To-Diagnosis $(\mathrm{HR} 0.96,95 \% \mathrm{CI}=[0.78-1.19], p$ $=0.426$ ). Only the tumor site statistically influenced the Time-To-Diagnosis: The Time-to-Diagnosis is shorter for breast cancer $(0.75$ months [0.30-1.9]) and longer for prostate cancer (4.69 months [1.6-29.7]) with an adjusted $\mathrm{HR}=0.27(95 \% \mathrm{CI}=[0.22-0.34], p<0.001)$.

Univariate associations between patients' characteristics and Time-To-Treatment are reported on Table 3. EDI was not associated with Time-To-Treatment $(p=0.324)$. After elimination of correlated variables, a multivariate analysis (Table 3 ) identified the tumor site as the only independently associated factor with Time-ToTreatment: patients with breast cancer have a shorter time 
to treatment than patients with prostate cancer (adjusted HR 0.32 [0.27-0.39], $p<0.001)$.

Strata analyses (Table 4) did not manage to identify any association between EDI-quintile and TimeTo-Diagnosis for any tumor site explored. T-staging at baseline was statistically associated with Time-ToDiagnosis for breast cancer, after a multivariate analysis $(p<0.001)$. Age at diagnosis and T-staging at baseline were statistically associated with Time-To-Diagnosis for prostate cancer, after multivariate analysis $(p=0.034$ and $p=0.034$, respectively). Metastases at baseline and performance status were associated with TimeTo-Diagnosis for Sarcoma $(p=0.002$ and $p=0.009$ respectively). After adjustment, no variables were found independently associated to Time-To-Diagnosis for patients with lung cancer or colorectal cancer.

Strata analyses (Table 5) did not manage either to identify association between deprivation and Time-ToTreatment, for any of the tumor sites explored. For prostate cancer, the health condition estimated by performance status was independently associated with a short Time-ToTreatment if it was good (PS $=1)(p<0.001)$. Similarly, the smaller the T staging was, the shorter was the Time-ToTreatment $(p=0.045)$. For colorectal cancer, few factors were identified as influencing the Time-To-Treatment: Being a man lead to a quicker treatment response $(p<$ $0.001)$, as well as having a small T staging $(p=0.006)$. Neither for sarcoma nor for breast cancer or lung cancer, were any factors identified as influencing Time-ToTreatment.

\section{DISCUSSION}

In this exhaustive, mono-centric population-based study, the primitive tumor site seems the main predictive factor for Time-to-diagnostic and Time-To-Treatment. The Socio Economic Status, estimated with the European District Index, has not been identified as modifying TimeTo-Diagnosis or Time-To-Treatment in this population. Even for inside strata analyses, that removed the strong tumor site effect, deprivation does not appear as a factor influencing Time-To-Diagnosis and Time-To-Treatment.

According to the tumor site, times could vary in the ratio of one to 6 for Time-To-Diagnosis : 0.75 month for breast cancer and 4.69 months for prostate cancer and of one to 3 for Time-To-Treatment : 0.75 month for breast cancer and 2.02 months for prostate cancer. These different observed times illustrate the heterogeneity of evolution and practices according to the tumor site:

Time-To-Diagnosis is shorter for breast cancer because of the screening practice, which shortens symptoms onset and which is the first step into a relatively standardized, prompt care path extending from first suspicion to completion of all treatments. On the contrary, the prostate cancer care path requires more time, since elevated prostatic specific antigen (PSA) generally lead first to a watchful follow-up rather than to an immediate biopsy, within the context of a slow growing tumor.

Time-To-Treatment has been established as a quality of care indicator worldwide : guidelines have been produced to regulate its maximum limit [27, 28]. It has been estimated in this study from 0.34 month for the sarcomas (featuring an emergency response to cancer) to 2.02 months for the prostate cancer, which is considered
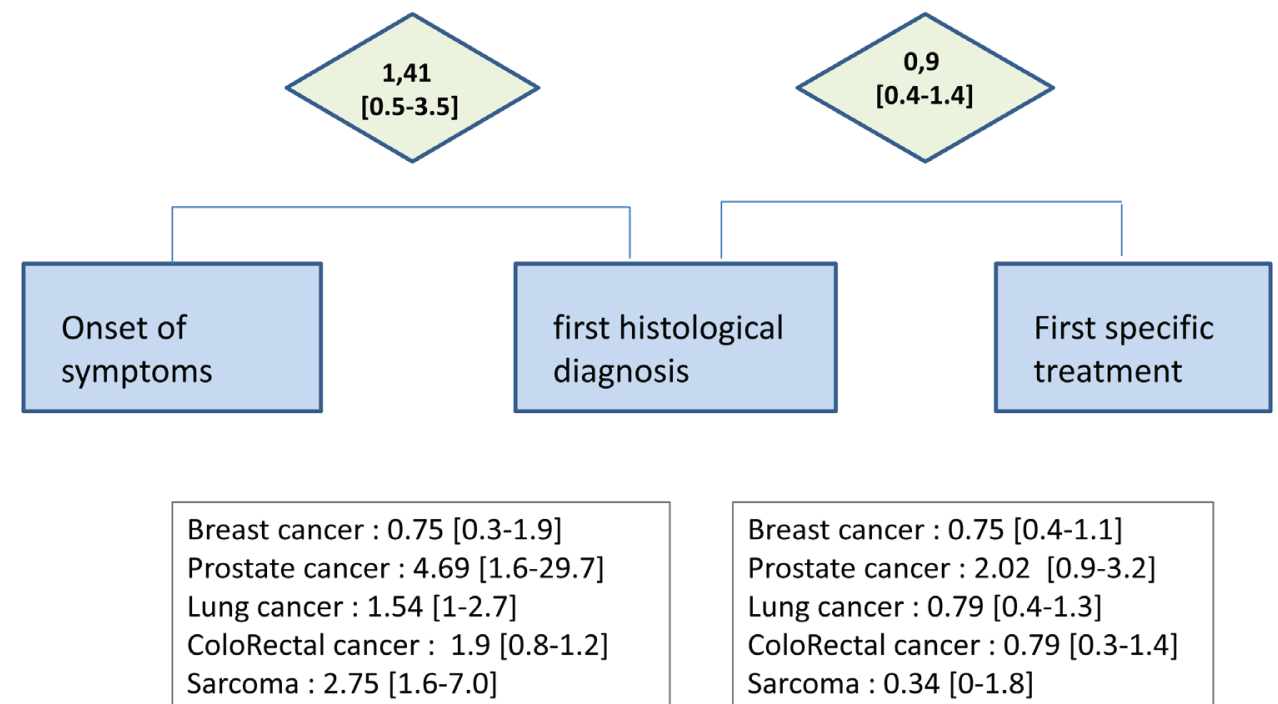

Figure 1 : Times between care intervals for the all 969 cancer patients included in the study, newly diagnosed and treated in the Saint Etienne Comprehensive Cancer Center, between the first of January 2013 and the 31 of december 2013. Times-to-diagnosis and Time-to-treatement are also given by tumor site. Times are in months, median [interquartile]. 
Table 4: strata analysis results : independents factors associated with Time to diagnosis, identified by multivariate analyses, for each tumor site

\begin{tabular}{|c|c|c|c|c|c|c|c|c|c|c|c|c|c|c|}
\hline & \multicolumn{3}{|c|}{ Breast cancer } & \multicolumn{3}{|c|}{ Prostate cancer } & \multicolumn{3}{|c|}{ Sarcoma } & \multicolumn{3}{|c|}{ Lung cancer } & \multicolumn{2}{|c|}{ Colorectal cancer } \\
\hline & univariate & & multivariate & univariate & & multivariate & univariate & & multivariate & univariate & & multivariate & univariate & multivariate \\
\hline & HR $[95 \% \mathrm{Cl}]$ & $\rho(\mathrm{LR})$ & HR $[95 \% \mathrm{Cl}] \quad \rho(\mathrm{LR})$ & HR $[95 \% \mathrm{Cl}]$ & $\rho(\mathrm{LR})$ & $\begin{array}{ll}H R[95 \% \mathrm{Cl}] & \stackrel{p}{(\mathrm{R})}) \\
& \end{array}$ & $H R[C l]$ & $\left(L^{p}\right)$ & AHR $[C l]$ & HR $[95 \%$ Cl] & $\begin{array}{c}p \\
(L R) \\
(R)\end{array}$ & $\begin{array}{ll}\text { AHR }[95 \% \mathrm{Cl}] & p \\
(\mathrm{LR})\end{array}$ & $H R[95 \% \mathrm{Cl}]$ & AHR $[95 \% \mathrm{Cl}] \quad p(\mathrm{LR})$ \\
\hline $\begin{array}{l}\text { AGE } \\
{\left[\begin{array}{l}{[19-55]} \\
{[56-65]} \\
{[66-74]} \\
{[75-92]}\end{array}\right.}\end{array}$ & $\begin{array}{c}1 \text { (reference) } \\
1.17[0.94-1.47] \\
1.19[50.92-1.53] \\
1.12[0.87-1.44] \\
\end{array}$ & 0.419 & & $\begin{array}{l}0.68[0.28-1.62] \\
1 \text { (reference) } \\
0.54[0.36-0.81] \\
0.67[0.43-1.04]\end{array}$ & 0.04 & $\begin{array}{cc}0 & \\
.71[0.27-1.9] & \\
1 \text { (reference) } & \mathbf{0 . 0 3 4} \\
0.52[0.33-0.8] & \\
0.55[0.34-0.9] & \end{array}$ & $\begin{array}{c}1 \text { (reference) } \\
0.66[0.23-1.9] \\
1.11[0.35-3.57] \\
0.84[0.37-1.89]\end{array}$ & 0.845 & & \begin{tabular}{|c|}
1 (reference) \\
$0.86[0.52-1.43]$ \\
$1.05[0.64-1.72]$ \\
$1.1[0.62-1.94]$
\end{tabular} & 0.726 & & \begin{tabular}{cc|}
1 (reference) & 0.879 \\
& \\
$0.98[0.54-1.77]$ & \\
$1.17[0.65-2.12]$ & \\
$1.12[0.62-2]$ &
\end{tabular} & \\
\hline $\begin{array}{c}\text { GENDER } \\
\text { Female } \\
\text { Male }\end{array}$ & $\begin{array}{c}1 \text { (reference) } \\
1.32[0.42-4.11]\end{array}$ & 0.649 & & NA & NA & & $\begin{array}{ll}1 \text { (references) } & 0 \\
0.6[0.29-1.23] & \end{array}$ & 0.172 & $\begin{array}{cc}1 \text { (reference) } & 0.623 \\
0.78[0.29-2.08] & \end{array}$ & $\begin{array}{c}1 \text { (reference) } \\
1.04[0.73-1.47]\end{array}$ & 0.848 & & \begin{tabular}{cc|}
1 (reference) & 0.89 \\
$0.97[0.67-1.42]$ &
\end{tabular} & \\
\hline $\begin{array}{c}\text { ECOG PS } \\
0 \\
1 \\
2 \\
>2 \\
\end{array}$ & $\begin{array}{c}1 \text { (reference) } \\
0.81[0.64-1.02] \\
1.14[0.64-2.03] \\
0.790 .33-1.92] \\
\end{array}$ & 0.287 & & $\begin{array}{c}1 \text { (reference) } \\
0.84[0.59-1.2] \\
2.59[1.38-4.87] \\
4.54[1.41-14.66]\end{array}$ & 0.005 & & $\begin{array}{c}1 \text { (reference) } \\
0.41[0.18-0.92] \\
1.29[0.34-4.89] \\
0.25[0.03-1.99] \\
\end{array}$ & 0.09 & $\begin{array}{cc}1 \text { (reference) } & 0.009 \\
0.23[0.09-0.61] & \\
1.01[0.2-5.2] & \\
0.1[0.01-1.71] & \\
\end{array}$ & \begin{tabular}{|c|}
1 (reference) \\
$1.26[0.79-2.01]$ \\
$1.76[1.02-3.03]$ \\
$2.27[1.01-5.1]$ \\
\end{tabular} & 0.102 & $\begin{array}{cc}1 \text { (reference) } & 0.359 \\
1.47[0.8-3.38] & \\
1.75[0.82-3.75] & \\
2.76[0.71-10.66] & \\
\end{array}$ & $\begin{array}{|cc|}1 \text { (reference) } & 0.433 \\
1.4[0.92-2.14] & \\
1.32[0.76-2.31] & \\
1.17[0.42-3.24] & \\
\end{array}$ & \\
\hline $\begin{array}{c}\text { QUINTILE } \\
\text { EDI } \\
1 \\
2 \\
3 \\
4 \\
4 \\
5 \\
\end{array}$ & $\begin{array}{c}1 \text { (reference) } \\
0.83[0.61-1.14] \\
0.9[0.66-1.23] \\
0.97[0.72-1.31] \\
1.01[0.77-1.34]\end{array}$ & 0.628 & $\begin{array}{ll}1 \text { (reference) } & 0.611 \\
0.85[0.62-1.16] & \\
0.97[0.71-1.32] & \\
1.01[0.75-1.37] & \\
1.05[0.79-1.4] & \\
\end{array}$ & $\begin{array}{c}1 \text { (reference)) } \\
1.13[0.67-1.92] \\
0.85[0.47-1.54] \\
1.72[0.96-3.06] \\
1.29[0.74-2.25]\end{array}$ & 0.103 & $\begin{array}{ll}1 \text { (references) } & 0.081 \\
1.42[0.8-2.51] & \\
1.03[0.54-1.97] & \\
1.91[1.02-3.58] & \\
1.79[0.93-3.43] & \\
\end{array}$ & $\begin{array}{c}1 \text { (references) } \\
1.04[0.26-4.24] \\
0.74[0.2-2.8] \\
1.8[0.41-7.78] \\
0.85[0.23-3.11] \\
\end{array}$ & 0.68 & $\begin{array}{cc}1 \text { (reference) } & 0.314 \\
0.92[0.12-7.28] & \\
0.85[0.12-6.12] & \\
3.56[0.49-25.9] & \\
1.11[0.14-8.8] & \\
\end{array}$ & \begin{tabular}{|c|}
1 (reference) \\
$1.06[0.59-1.99]$ \\
$0.95[0.52-1.75]$ \\
$1.0[0.56-1.81]$ \\
$0.95[0.55-1.65]$ \\
\end{tabular} & 0.994 & $\begin{array}{cc}1 \text { (reference) } & 0.982 \\
1.03[0.46-2.32] & \\
0.97[0.44-2.13] & \\
1.2[0.54-2.67] & \\
1.13[0.53-2.38] & \\
\end{array}$ & $\begin{array}{|ll|}1 \text { (reference) } & 0.755 \\
0.91[0.47-1.77] & \\
0.88[0.44-1.75] & \\
0.69[0.34-1.38] & \\
0.98[0.53-1.81] & \\
\end{array}$ & $\begin{array}{cc}1 \text { (reference) } & 0.886 \\
0.87[0.42-1.78] & \\
0.9[0.43-1.9] & \\
0.73[0.34-1.53] & \\
0.97[0.5-1.9] & \\
\end{array}$ \\
\hline $\begin{array}{c}\text { staging } \\
1 \\
2 \\
3 \\
4 \\
\end{array}$ & $\begin{array}{c}1 \text { (reference) } \\
0.8[0.66-0.98] \\
0.53[0.33-0.83] \\
0.39[0.23-0.64] \\
\end{array}$ & $<0.001$ & $\begin{array}{cc}1 \text { (reference) } & <0.001 \\
0.79[0.64-0.97] & \\
0.52[0.33-0.81] & \\
0.36[0.21-0.61] & \\
\end{array}$ & $\begin{array}{c}1 \text { (reference) } \\
1.51[1.05-2.17] \\
1.29[0.83-2.01] \\
2.37[0.32-17.37]\end{array}$ & 0.153 & $\begin{array}{cc}1 \text { (reference) } & \mathbf{0 . 0 3 4} \\
1.61[1.07-2.45] & \\
1.42[0.86-2.34] & \\
2.2[0.3-16.69] & \\
\end{array}$ & $\begin{array}{c}1 \text { (reference) } \\
\text { NA } \\
\text { NA } \\
\text { NA }\end{array}$ & 0.174 & & \begin{tabular}{|c|}
1 (reference) \\
$1.7[0.92-3.14]$ \\
$1.26[0.67-2.4]$ \\
$0.96[0.49-1.91]$ \\
\end{tabular} & 0.171 & $\begin{array}{cc}1 \text { (reference) } & 0.145 \\
1.7[0.86-3.38] & \\
1.24[0.61-2.53] & \\
0.83[0.39-1.76] & \\
\end{array}$ & \begin{tabular}{cc|}
1 (reference) & 0.222 \\
$0.38[0.09-1.54]$ & \\
$0.32[0.1-1.05]$ & \\
$0.25[0.08-0.85]$ & \\
\end{tabular} & \\
\hline $\begin{array}{c}\text { N staging } \\
0 \\
1 \\
2 \\
3\end{array}$ & $\begin{array}{c}1 \text { (reference) } \\
0.87[0.71-1.06] \\
0.8[0.56-1.16] \\
0.43[0.22-0.84]\end{array}$ & 0.021 & & $\begin{array}{c}1 \text { (referenoe) } \\
2.54[1.16-5.55] \\
\text { NA } \\
\text { NA }\end{array}$ & 0.038 & & $\begin{array}{c}1 \text { (referenoe) } \\
0.91[0.16-5.1] \\
7.31[0.44-121] \\
\text { NA }\end{array}$ & 0.414 & & \begin{tabular}{|c|}
1 (reference) \\
$1.16[0.57-2.35]$ \\
$1.37[0.78-2.41]$ \\
$1.31[0.67-2.57]$ \\
\end{tabular} & 0.707 & & \begin{tabular}{cc|}
1 (reference) & 0.141 \\
$0.66[0.42-1.06]$ & \\
$0.97[0.55-1.73]$ & \\
NA & \\
\end{tabular} & $\begin{array}{cc}1 \text { (reference) } & 0.189 \\
0.67[0.42-1.09] & \\
0.95[0.52-1.76] & \\
\text { NA } & \end{array}$ \\
\hline $\begin{array}{c}\text { M status } \\
0 \\
1\end{array}$ & $\begin{array}{c}1 \text { (reference) } \\
0.62[0.39-0.99]\end{array}$ & 0.031 & & $\begin{array}{c}1 \text { (reference) } \\
3.29[1.89-5.72]\end{array}$ & $<0.001$ & & $\begin{array}{cc}1 \text { (reference) } & 0 \\
0.6[0.29-1.23] & \end{array}$ & 0.125 & $\begin{array}{cc}1 \text { (referenoe) } & 0.002 \\
0.21[0.07-0.02] & \end{array}$ & $\begin{array}{c}1 \text { (reference) } \\
0.92[0.65-1.29]\end{array}$ & 0.62 & & \begin{tabular}{cc|}
1 (reference) & 0.828 \\
$1.04[0.71-1.52]$ &
\end{tabular} & \\
\hline
\end{tabular}

Table 5: strata analysis results : independents factors associated with Time to Treatment identified by multivariate analyses, for each tumor site

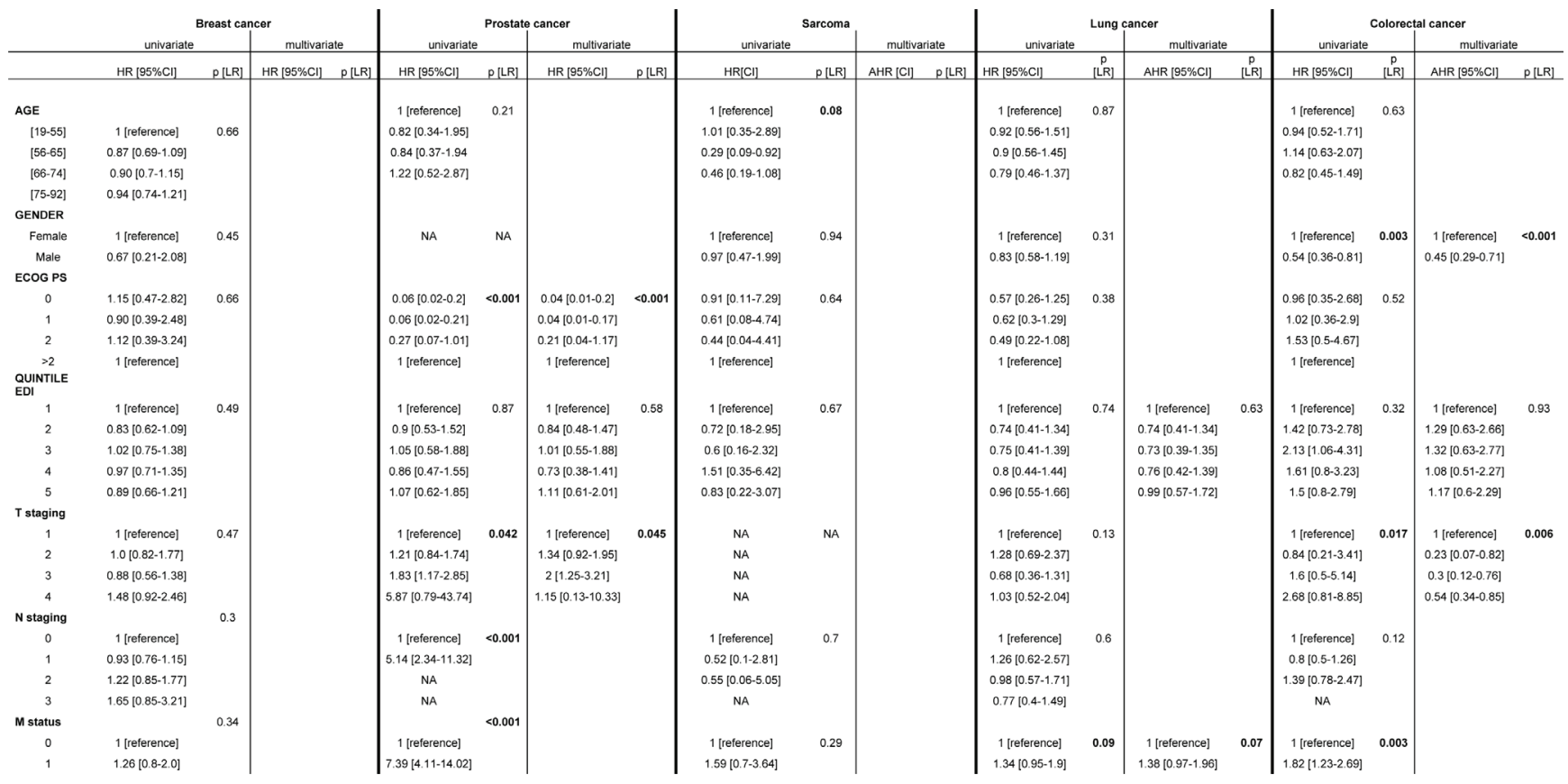

as an indolent cancer. The median Time-To-Treatment is 0,9 months (27,2 days) for all cancers in this study, which is under the threshold established by guidelines reporting the preferable delays for treatment [27, 28]: 28 days in the USA and 31 days in the UK. If prostate cancer is excluded, all others tumor sites present an adequate speed of treatment response (from 0.34 to 0.79 month).

Tumor site strata analyses brought some 
information: The medical factors related to the disease ( $\mathrm{T}$ staging for breast cancer and presence of metastases for sarcoma ) confirmed what is observed in practice : the more symptomatic the tumor is, the sooner it is detected. Other factors ( performance status, metastatic status) appear to have been taken into account concerning the decision to treat the process so that the best and least harmful care path can be scheduled. We found no explanation for the difference in Time-To-Treatment between woman and men for colorectal cancer. This needs to be further explored. What's more, a lack of power into these strata analyses must be considered and does not allow us to conclude firmly.

This study is the first to explore elapsed times from symptoms to first treatment in 5 cancers, and in France. Its strength resides in the setting of the data collection: The sample was an absolute exhaustive collection of patients: All patients admitted to the Cancer Comprehensive Center, for one year, were suffering from the 4 more frequent and one rare cancers, with no missing data. What's more, this sample can be considered as highly representative of a rural French population because of the particular recruitment of this center: Being the only center in this wide area with both oncologic and radiotherapeutic departments, this center is in monopoly in the Loire County. No selection bias can be here reported. This study is also one of the first to use the new French EDI to assess Socio-economic deprivation.

This study didn't identify any association between Time-To-Diagnosis / Time-To-Treatment and socioeconomic deprivation. In a review of studies examining the association of cancer survival with socio-economic status, Woods et al [32] identified 38 articles and mentioned 14 studies having reported no association between socio-economic status and cancer survival. What's more, in ecological studies using deprivation index, differences were systematically smaller, due to the inaccuracy of the estimate. Even in studies identifying an impact of the socio-economic status on survival, the estimated effect was often moderate. More recent studies confirmed this tendency : individual deprivation estimates [33] lead to a stronger association than ecological ones $[34,35]$. All of the recent studies without any association between socio-economic deprivation and cancer outcomes used the ecological Index, either to explore relationships with cancer survival [36], cancer treatment [8, 37], or HPV vaccination [38].

These results lead to this assumption: an ecological index is not such a good estimate for the individual patient socioeconomic status. The deprivation score for an area cannot apply to all its residents. People can live in a deprived area, without being themselves deprived. What's more the French EDI is a new index, which has not demonstrated its psychometric validity on the long term for now. This Index has been used in this French area (Loire county) which is mostly a rural county. Yet,
Bertin et al, demonstrated recently that a deprivation index was less valid in rural places [39]: the homogeneity for socioeconomic status in each geographical area is less existent.

Another assumption can be that the cancer outcomes chosen were not relevant. Yet these outcomes have already been identified as quality-of-care indicators as well as proxy for evolution and survival [27, 28, 40, 41]. Saint Jacques et al and Dalton et al succeeded to identify an association between longer Time-To-Treatment and low educational level for breast cancer [42], and lung cancer [25]. Berglund underlined an impact of the socioeconomic status (measured by combining income, education level and occupation ) on the Time-To-Treatment for lung cancer [43]. So these indicators seemed theoretically relevant as cancer end points to explore.

The last assumption could be that in this particular setting, the socioeconomic status did not impact the waiting times. But we believe the explanation should be searched for elsewhere, in an index that measures socioeconomic deprivation more appropriately, probably with individual level data.

In practice, this study underlined the difficulty to assess individual socio-economic level, and by that, to assess its impact on cancer-related health outcomes. The only postal address seams not sufficient, at least for such a rural area, to provide an exact overview of inequalities. If health care inequalities are considered by the competent authorities to be mandatory issues to be tackle, the hospital routine data collection should require additional characteristics to be gathered, for each patient. Those characteristics could allow a global evaluation of the patient beyond its medical condition. What those extra data should be composed of remains to be settle down.

Our study faced several limitations: More variables could have been studied, but we did not access more, in an exhaustive way. But even with these few, we identified other factors influencing the Time-To-Diagnosis and the Time-To-Treatment. We can assume that with even more variables, we would have had the same results. Our study is a monocentric study, which shortens the specter of representation. Yet as we said above, the patients admitted to this center are particularly diverse and representative of the whole county population. As mentioned previously, an ecological geocoded index (EDI) has been used to estimate patients' deprivation. This geographical estimation may not be enough relevant, either because the patients' sample is peculiar (people who live in rural areas), or because the EDI is a non-individual estimation. Labbe et al [44] recently demonstrated how a specific and individual French score (EPICES score) may be more reliable to diagnose deprivation. However, this score requires access to individual data that are usually unavailable in databases, while place of residence (allowing the use of the EDI) is systematically collected. Labbe et al proposed to aggregate this score to perform an ecological index: The ecological 
EPICES score could then be used to estimate, perhaps more precisely, French patients' deprivation. However, this score would not address the problem of comparison across countries which is allowed by the EDI. Thus, although less accurate, EDI may provide an opportunity in both assessing deprivation and comparison across settings. Five tumor sites have been explored in this study. It allows the results to give a fair representation of the medical practices of a cancer comprehensive center. Yet, this heterogeneous population led to a lack of power for all subgroup analysis.

Despite all these limits, the methodology used remains adequate and allows us to conclude on an absence of a major influence of the patients' deprivation estimated with the EDI on waiting times, but on a major influence of the tumor site on those waiting times, in this setting.

\section{CONCLUSIONS}

Deprivation estimated by European deprivation Index French version, does not appear to be related to an extension of the time to diagnosis or time to treatment in our real-life population of cancer patients. Cancer location and the tumor staging at baseline are much more powerful factors explaining variation in waiting times. Waiting times estimated in this study are concordant with the maximum delay recommended for the cancer care worldwide, and translate good quality-of-care in this setting. Yet we cannot stop at these rather soothing results. Further research should be done to clearly identify and measure, at an individual-level, more sensitive frailty factors that could be responsible for delays in care. Developing actions targeting those fragile populations would be the next step.

\section{PATIENTS AND METHODS}

\section{Design}

A retrospective mono-centered cohort study was performed.

\section{Population}

We included retrospectively all consecutive incoming adult patients diagnosed for breast cancer (BC), prostate cancer (PC), colorectal cancer (CRC), lung cancer (LC) or sarcoma (S) and admitted to the comprehensive cancer centre of Saint Etienne (France) between the 1st of January 2013 and the 31st of December 2013. BCs were both ductal carcinoma and adenoma carcinoma. CRCs were defined as cancer arising from the cecum to the rectum. LC includes small cell carcinoma and nonsmall cell carcinoma. S included soft tissue sarcoma, osteosarcoma and Darrier-Ferrand syndrome. Patients were included only if they had a confirmed histological malignancy. Patients were excluded if they had tumor relapse, hematological malignancies or other tumor site.

\section{Data collection}

Once included, data for all patients were collected from two databases: demographical data were collected from the administrative database and Medical data were collected from the medical information system of the Institute. Missing data were gathered from individual medical files.

Clinical data were gathered : clinical condition status at baseline using Eastern Cooperative Oncology Group (ECOG) performance status (PS), cancer extension according to the TNM staging and grading (Scarf Bloom and Richardson, SBR grade for patients with BC, Gleason score for patients with PC, grading for patients with sarcoma). Symptomatology history was reconstructed by the clinician with direct examination during the first consultation. Onset of symptoms was collected according to the type of cancer : date of first clinical signs (pain, tumor hardening, dysuria, hematuria, cough, hemoptysis, rectal bleeding...), or date of the first abnormal radiological or biological result for cancer screening (abnormal mammography, colonoscopy, PSA increase). Consecutive treatments were reported, as well as follow up. Patient socio-demographic characteristics and postal address were also recorded.

Date of diagnosis was defined as the date of the first histological proof of malignancies (by biopsy or cytological, otherwise surgical sample). Time-ToDiagnosis was the time between onset of symptoms and date of diagnosis. Time-to-treatment was the time between the date of diagnosis and the date of the first specific treatment (surgery, chemotherapy, hormone therapy, radiation therapy, surveillance or best supportive cares).

\section{French EDI}

The EDI is an adaptable transnational ecological deprivation index. It has been developed according to a common definition of deprivation- physical and socialwhile maintaining the specificity of each country. This index combines on one hand, individual data from a European survey on poverty launched by the European Commission (EU-SILC) [31], and in the other hand, data from the population census of each country. Those characteristics (identical study design for all countries, dynamic cohort), allows this index to be transposable in time and from one country to another and should help in characterize and compare socio-economic characteristics of a population across settings. This ecological deprivation index has been built and used for the first time in France in 2012 [31, 32]. The EDI can be replicated in 24 other 
European countries. The French EDI is divided in 5 quintiles; from 1 (least deprived) to 5 (most deprived).

The deprivation level for each patient was estimated by assigning him the EDI quintile of his place of house, deducted from his postal address (the only geographical data we could retrospectively gathered). Deprivation was therefore estimated rather than individually assessed. The postal address of each patient was geocoded on global positioning system (GPS) coordinates using Google Map ${ }^{\circledR}$ (Google Inc, California, USA); these coordinates were linked to an EDI quintile using an area-based measure, which was attributed to the patient.

\section{Statistical analysis}

Descriptive statistics were used to characterize patients' population (median and inter-quartile range for continuous variables; frequencies and proportions for categorical variables; percentage of missing data). TimeTo-Diagnosis and Time-To-Treatment were estimated using a censored data model. The unadjusted associations between patients' characteristics and Time-To-Diagnosis as well as Time-To-Treatment were tested with log-rank comparisons. Multivariate analyses were performed using Cox regression. Variables with a $p<0.20$ in the univariate analyses were included in the multivariate analyses with a significance threshold of $p<0.05$. The association of EDI and Time-To-Diagnosis, as well as Time-To-Treatment was analyzed by tumor site strata. Statistical analyses were performed with R 3.0.2

\section{AKNOWLEDGMENTS}

We would like to thank Carole Pornet and Guy Launoy who gave us access to the French EDI database for each IRIS zone. We would like to thank Susan Guillaumond for translation and editing services.

\section{FUNDING}

This work was supported by the Hygée centre: manuscript translation and editing fees

\section{CONFLICTS OF INTEREST}

The authors declare no conflict of interest

\section{Author contributions}

FC, $\mathrm{AB}$ and $\mathrm{NM}$ conceived the project. GM collected all the data. GM, FT and MO did the statistical analyses. GM wrote the first draft and revised drafts of the manuscript. FC, AB, JPJ, PF, NM, MO, FT critically revised the manuscript for important intellectual content.
The final version of the manuscript was approved by all the authors.

GM and AB had full access to all of the data in the study and take responsibility for the integrity of the data and the accuracy of the data analysis. $\mathrm{AB}$ is the guarantor for the study

\section{REFERENCES}

1 Mackenbach JP, Kunst AE, Cavelaars AE, Groenhof F, Geurts JJ. Socioeconomic inequalities in morbidity and mortality in western Europe. The EU Working Group on Socioeconomic Inequalities in Health. Lancet 1997;349:1655-9.

2 Mackenbach JP, Stirbu I, Roskam AJ, Schaap MM, Menvielle G, Leinsalu M, Kunst AE; European Union Working Group on Socioeconomic Inequalities in Health. Socioeconomic inequalities in health in 22 European countries. N Engl J Med 2008;358:2468-81.

3 Ferlay J, Soerjomataram I, Dikshit R, Eser S, Mathers C, Rebelo M, Parkin DM, Forman D, Bray F. Cancer incidence and mortality worldwide: Sources, methods and major patterns in GLOBOCAN 2012. Int $\mathrm{J}$ Cancer 2015;136:E359-386.

4 Brewster DH, Thomson CS, Hole DJ, Black RJ, Stroner PL, Gillis CR. Relation between socioeconomic status and tumour stage in patients with breast, colorectal, ovarian, and lung cancer: results from four national, population based studies. BMJ 2001;322:830-1.

5 Chor JS, Lam HC, Chan A, Lee HM, Fok E, Griffiths S, Cheung P. Socioeconomic disparity in breast cancer detection in Hong Kong - a high income city: retrospective epidemiological study using the Breast Cancer Registry. PLoS ONE 2014;9:e107630.

6 Bryere J, Dejardin O, Bouvier V, Colonna M, Guizard AV, Troussard X, Pornet C,Galateau-Salle F, Bara S, Launay L, Guittet L, Launoy G. Socioeconomic environment and cancer incidence: a French population-based study in Normandy. BMC Cancer 2014; 14:87.

7 Huismans AM, Niebling MG, Wevers KP, Schuurman MS, Hoekstra HJ. Factors influencing the use of sentinel lymph node biopsy in the Netherlands. Ann Surg Oncol 2014;21:3395-400.

8 Aarts MJ, Hamelinck VC, Bastiaannet E, Coebergh JW, Liefers GJ, Voogd AC, van der Sangen M, Louwman WJ. Small but significant socioeconomic inequalities in axillary staging and treatment of breast cancer in the Netherlands. Br J Cancer 2012;107:12-7.

9 Doll R, Peto R. The causes of cancer: quantitative estimates of avoidable risks of cancer in the United States today. J Natl Cancer Inst 1981;66:1191-308.

10 Schrijvers CT, Mackenbach JP. Cancer patient survival by socioeconomic status in seven countries: a review for six common cancer sites [corrected]. J Epidemiol Community 
Health 1994;48:441-6.

11 Faggiano F, Partanen T, Kogevinas M, Boffetta P. Socioeconomic differences in cancer incidence and mortality. IARC Sci Publ. 1997;(138):65-176.

12 Fernandez E, Borrell C. Cancer mortality by educational level in the city of Barcelona. Br J Cancer 1999;79:684-9.

13 Bradley CJ, Given CW, Roberts C. Disparities in cancer diagnosis and survival. Cancer 2001;91:178-88.

14 Holm LV, Hansen DG, Larsen PV, Johansen C, Vedsted P, Bergholdt SH, Kragstrup

J, Søndergaard J. Social inequality in cancer rehabilitation: a population-based cohort study. Acta Oncol 2013;52:410-22.

15 von Euler-Chelpin M, Olsen AH, Njor S, Jensen A, Vejborg I, Schwartz W, Lynge E. Does educational level determine screening participation? Eur J Cancer Prev 2008; 17:273-8.

16 von Wagner C, Baio G, Raine R, Snowball J, Morris S, Atkin W, Obichere A,Handley G, Logan RF, Rainbow S, Smith S, Halloran S, Wardle J. Inequalities in participation in an organized national colorectal cancer screening programme: results from the first 2.6 million invitations in England. Int J Epidemiol 2011;40:712-8.

17 Hahm MI, Park EC, Choi KS, Lee HY, Park JH, Park S. Inequalities in adoption of cancer screening from a diffusion of innovation perspective: identification of late adopters. Cancer Epidemiol 2011;35:90-6.

18 Damiani G, Federico B, Basso D, Ronconi A, Bianchi CB, Anzellotti GM, Nasi G, Sassi F, Ricciardi W.. Socioeconomic disparities in the uptake of breast and cervical cancer screening in Italy: a cross sectional study. BMC Public Health 2012;12:99.

19 McKenzie F, Ives A, Jeffreys M. Socio-economic inequalities in survival from screen-detected breast cancer in South West England: population-based cohort study. Eur J Public Health 2012;22:418-22.

20 Hellquist BN, Czene K, Hjälm A, Nyström L, Jonsson H. Effectiveness of population-based service screening with mammography for women ages 40 to 49 years with a high or low risk of breast cancer: Socioeconomic status, parity, and age at birth of first child. Cancer Published Online First: 19 September 2014.

21 Rondet C, Lapostolle A, Soler M, Grillo F, Parizot I, Chauvin P. Are immigrants and nationals born to immigrants at higher risk for delayed or no lifetime breast and cervical cancer screening? The results from a population-based survey in Paris metropolitan area in 2010. PLoS ONE 2014;9:e87046.

22 Grillo F, Vallée J, Chauvin P. Inequalities in cervical cancer screening for women with or without a regular consulting in primary care for gynaecological health, in Paris, France. Prev Med 2012;54:259-65.

23 Pornet C, Dejardin O, Morlais F, Bouvier V, Launoy G. Socioeconomic and healthcare supply statistical determinants of compliance to mammography screening programs: a multilevel analysis in Calvados, France. Cancer
Epidemiol 2010;34:309-15.

24 Dickens C, Joffe M, Jacobson J, Venter F, Schüz J, Cubasch $\mathrm{H}$, McCormack V. Stage at breast cancer diagnosis and distance from diagnostic hospital in a periurban setting: a South African public hospital case series of over 1,000 women. Int J Cancer 2014;135:2173-82.

25 Dalton SO, Frederiksen BL, Jacobsen E, Steding-Jessen M, Østerlind K, Schüz J,Osler M, Johansen C. Socioeconomic position, stage of lung cancer and time between referral and diagnosis in Denmark, 2001-2008. Br J Cancer 2011;105:1042-8.

26 Ciccone G, Prastaro C, Ivaldi C, Giacometti R, Vineis P. Access to hospital care, clinical stage and survival from colorectal cancer according to socio-economic status. Ann Oncol 2000;11:1201-4.

27 Target Wait Times for Cancer Surgery in Ontario. https:// www.cancercare.on.ca/common/pages/UserFile.aspx?fileId $=43244$ (accessed 14 May2015).

28 Health D of. Publication of Cancer Reform Strategy, December 2007. http://webarchive.nationalarchives.gov. uk/+/www.dh.gov.uk/en/Healthcare/Cancer/DH_091120 (accessed 14 May2015).

29 Townsend P. Deprivation. Journal of Social Policy 1987;16:125-46.

30 Poncet F, Delafosse P, Seigneurin A, Exbrayat C, Colonna M. Determinants of participation in organized colorectal cancer screening in Isère (France). Clin Res Hepatol Gastroenterol 2013;37:193-9.

31 Pornet C, Delpierre C, Dejardin O, Grosclaude P, Launay L, Guittet L, Lang T, Launoy G Construction of an adaptable European transnational ecological deprivation index: the French version. J Epidemiol Community Health 2012;66:982-9.

32 Woods LM, Rachet B, Coleman MP. Origins of socioeconomic inequalities in cancer survival: a review. Ann Oncol 2006;17:5-19.

33 Li X, Sundquist J, Zöller B, Sundquist K. Neighborhood deprivation and lung cancer incidence and mortality: a multilevel analysis from Sweden. J Thorac Oncol 2015;10:256-63.

34 Ouédraogo S, Dabakuyo-Yonli TS, Roussot A, Pornet C, Sarlin N, Lunaud P,Desmidt P, Quantin C, Chauvin F, Dancourt V, Arveux P European transnational ecological deprivation index and participation in population-based breast cancer screening programmes in France. Prev Med 2014;63:103-8.

35 Rice LJ, Jiang C, Wilson SM, Burwell-Naney K, Samantapudi A, Zhang H. Use of segregation indices, Townsend Index, and air toxics data to assess lifetime cancer risk disparities in metropolitan Charleston, South Carolina, USA. Int J Environ Res Public Health 2014;11:5510-26.

36 Abdel-Rahman ME, Butler J, Sydes MR, Parmar MK, Gordon E, Harper P, WilliamsC, Crook A, Sandercock J, 
Swart AM, Rachet B, Coleman MP; ICON2 and ICON3 investigators. No socioeconomic inequalities in ovarian cancer survival within two randomised clinical trials. Br J Cancer 2014;111:589-97.

37 Vandergrift JL, Niland JC, Theriault RL, Edge SB, Wong YN, Loftus LS, Breslin TM, Hudis CA, Javid SH, Rugo HS, Silver SM, Lepisto EM, Weeks JC. Time to adjuvant chemotherapy for breast cancer in National Comprehensive Cancer Network institutions. J Natl Cancer Inst 2013;105:104-12.

38 Hughes A, Mesher D, White J, Soldan K. Coverage of the English national human papillomavirus (HPV) immunisation programme among 12 to 17 year-old females by area-level deprivation score, England, 2008 to 2011. Euro Surveill 2014;19.

39 Bertin M, Chevrier C, Pelé F, Serrano-Chavez T, Cordier S, Viel JF. Can a deprivation index be used legitimately over both urban and rural areas? Int J Health Geogr 2014;13:22.

40 Whynes DK, Frew EJ, Manghan CM, Scholefield JH, Hardcastle JD. Colorectal cancer, screening and survival: the influence of socio-economic deprivation. Public Health 2003;117:389-95.

41 Rayson D, Saint-Jacques N, Younis T, Meadows J, Dewar R. Comparison of elapsed times from breast cancer detection to first adjuvant therapy in Nova Scotia in 1999/2000 and 2003/04. CMAJ 2007;176:327-32.

42 Saint-Jacques N, Younis T, Dewar R, Rayson D. Wait times for breast cancer care. Br J Cancer 2007;96:162-8.

43 Berglund A, Holmberg L, Tishelman C, Wagenius G, Eaker $\mathrm{S}$, Lambe M. Social inequalities in non-small cell lung cancer management and survival: a population-based study in central Sweden. Thorax 2010;65:327-33.

44 Labbe E, Blanquet M, Gerbaud L, Poirier G, Sass C, Vendittelli F, Moulin JJ. New reliable index to measure individual deprivation: the EPICES score. Eur J Public Health. 2015;25:604-9. 